\title{
Waste gasification in an up-draft fixed-bed gasifier: experimental study and model validation
}

\author{
N. Verdone, P. De Filippis, M. Scarsella \& B. de Caprariis \\ Chemical Engineering Department, Sapienza University of Rome, Italy
}

\begin{abstract}
Gasification has been identified as a key technology to enhance the environmental tolerability of low quality fuels such as waste and biomass. In this work the performances of a laboratory scale gasification process fed with waste are reported.

Among the several technical choices, we selected the up-draft fixed-bed gasifier as an interesting solution for heat generation in small-scale applications, due to the characteristics of simple geometry and low cost.

The experimental setup is composed by an up-draft gasifier followed by a reactor used as filter to remove the particulate and as second thermal and catalytic stage to convert the produced tar in lighter species. A literature model has been adapted to the case under study to analyse the influence of operative parameters such as oxidant flow rate (equivalent and air/steam ratio values) and gasification temperature of the process. The original literature model considers the species gas evolution along the axial coordinate only, and does not include time dependency. To make the model time dependent, the consumption time of the gasification fuel bed estimated from experimental tests was introduced. Since the oxidation zone is below the gasification one, the initial species concentrations were set as the species concentrations produced at the end of the oxidation zone, calculated with an atom mass balance considering a complete char combustion. Since the model concerns only the gasification, the up-draft process was split into two consecutive steps to allow direct comparison between experimental and simulated data: first the drying and pyrolysis processes and then the fixed bed gasification. The model was successfully validated with experimental data and then it was used to predict the operative parameters that determine the optimal syngas composition. The best syngas composition $(35 \%$
\end{abstract}


$\mathrm{CO}$ and $10 \% \mathrm{H}_{2}$ ) was obtained with an equivalent ratio of 0.6 and a bed temperature of $1100 \mathrm{~K}$.

Keywords: auto fluff, disposal, gasification, energy recovery.

\section{Introduction}

Automotive shredder residue (ASR) or auto fluff is generated by technologies that recover non-ferrous metals and plastics from end-of-life vehicles, appliances and other light scrap. The main flow of ASRs is generated by the shredding of End-of-Life Vehicles (ELVs). The ASR is principally composed of textiles (25\%), plastic (23\%), sponge (17\%), and sand and solids (16\%). [1] The ASR represent the $20 \%$ of the ELVs that is not recycled and it is disposed in landfill in the majority of the EU country [2]. Sometimes, the presence of heavy metals and chloride from metals and PVC respectively makes ASR a hazardous waste causing increasing costs for its disposal.

The incineration is another possibility for the ASRs disposal, but the high content of inert leads to a low grade heating value making difficult the combustion of the ASR alone. Usually the co-combustion with municipal solid waste is preferred.

The quantity of ASR is foreseen to rise in the next years because of the increasing amount of polymers replacing metals in new vehicles. ASR valorisation treatments are necessary according to the limit of $13 \mathrm{MJ} / \mathrm{kg}$ stated for waste disposal by the European Directive 1999/31/EC and according to the Directive 2000/53/EC that claims for ELVs at least $85 \%$ recycling rate and $95 \%$ recovery rate by the year 2015, thus allowing the disposal in landfill for maximum 5\% ELV total weight [3]. Thus energy recovery from ASR will become one of the most attractive possibility to dispose of auto fluff.

In this work we propose to recover energy from auto fluff by gasification. In the gasification process, a combustible gas from a solid fuel with low grade heating value is produced. We selected the up-draft fixed-bed gasifier as an interesting solution for heat generation due to the characteristics of simple geometry and low cost.

\section{Experimental set-up}

\subsection{Experimental apparatus}

A laboratory-scale gasification plant was designed and constructed. Its main components are schematically represented in Figure 1. The plant is composed by an updraft gasifier followed by a catalytic reforming reactor, where the tar cracking occurs and the dragged particulate gasification reactions are completed. The catalyst used in the reforming reactor is made of aluminium oxide. The two reactors are cylindrical steel tubes of $4 \mathrm{~cm}$ diameter $(D)$ and $60 \mathrm{~cm}$ length $(L)$. The high value of the $L / D$ reactor ratio makes difficult to have an autothermal process, therefore the two reactors are heated by external tubular ovens. A grate, 
placed at $10 \mathrm{~cm}$ from the bottom of the gasifier, is used as support for the solid combustible and as air distributor. The fuel can be injected continuously through a cochlea whereas the ash removal is discontinuous. The two gasification agents, steam and air, are premixed, preheated and then injected into the reactor in counter-current with respect to the solid flow.

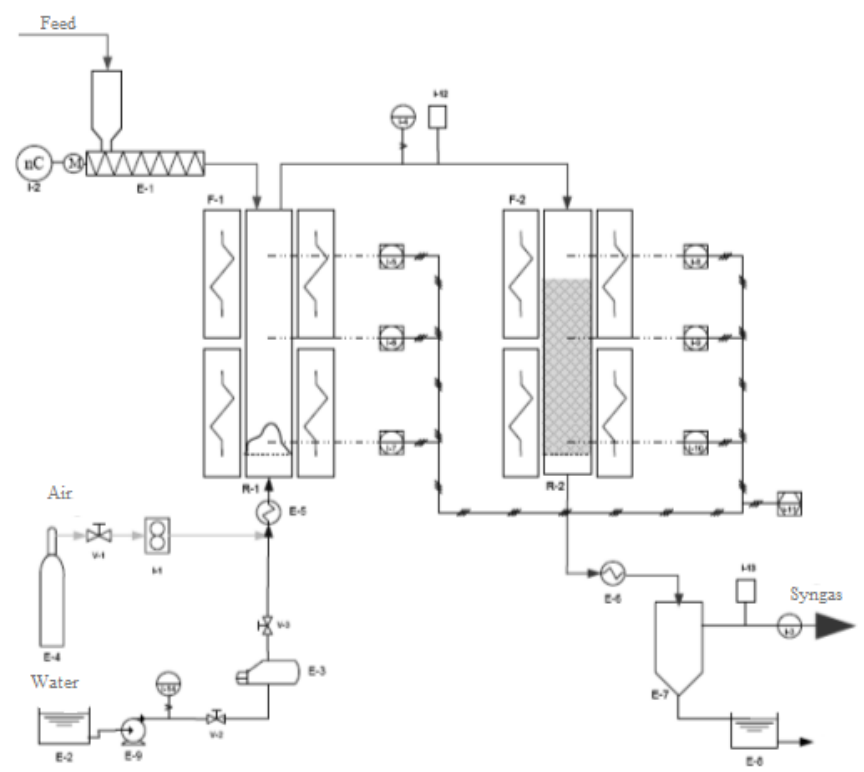

Figure 1: Laboratory scale plant.

Temperature profiles along the gasifier axis are measured by four thermocouples placed in a ceramic protective tube. The $\mathrm{CO}, \mathrm{CO}_{2}$ and $\mathrm{CH}_{4}$ concentrations are monitored continuously. The $\mathrm{H}_{2}$ concentration is measured with a gas chromatograph every $15 \mathrm{~min}$. The plant is equipped with two gas outflows: at the exit of the gasifier and at the exit of the reforming reactor. A condenser for the collection of the vapours produced during the pyrolysis is placed after the reforming reactor.

\subsection{Materials}

ASR is a heterogeneous material composed by a mixture of plastics, rubber, resins and textiles, and by a small amount of glass fragment and unrecovered metals. Because of the heterogeneity of these materials, samples were first accurately grinded and mixed. The immediate and elemental analyses were performed and the calorific value was calculated experimentally with a Mahler bomb calorimeter. Average values of these properties are reported in Table 1. 
Table 1: $\quad$ ASRs properties.

\begin{tabular}{cc}
\hline Immediate Analysis & Value \\
\hline Humidity (\% mass) & $5 \%$ \\
Volatile matter (\% mass dry basis) & $33 \%$ \\
Fixed carbon (\% mass dry basis) & $37 \%$ \\
Ash (\% mass dry basis) & $30 \%$ \\
\hline Upper calorific value $(\mathrm{MJ} / \mathrm{kg})$ & 16.2 \\
\hline Elemental Analysis & $(\%$ mass dry basis $)$ \\
\hline $\mathrm{C}$ & 20 \\
$\mathrm{H}$ & 6.1 \\
$\mathrm{O}$ & 16 \\
$\mathrm{~N}$ & 0.5 \\
$\mathrm{~S}$ & 0.3 \\
$\mathrm{Cl}$ & $<0.1$ \\
\hline
\end{tabular}

\section{Model}

A literature model [4] for a down-draft gasifier was adapted to our case. The model is mono-dimensional, the bed and gas properties variations were considered negligible, and the gases were assumed to behave ideally. In an updraft gasifier, the gasification zone is above the combustion ones, so the input parameters of the model (initial gas concentration and initial temperature) are the output of the combustion zones. These initial values were calculated by an elemental mass balances, considering that all the oxygen fed into the reactor was consumed by the combustion reaction. The combustion reaction is:

$$
\mathrm{CH}_{0.371} \mathrm{O}_{0.071}+\mathrm{yO}_{2}+\mathrm{zN}_{2}+\mathrm{wH}_{2} \mathrm{O}=\mathrm{x}_{1} \mathrm{C}+\mathrm{x}_{2} \mathrm{H}_{2} \mathrm{O}+\mathrm{x}_{3} \mathrm{CO}_{2}+\mathrm{x}_{4} \mathrm{CH}_{4}+\mathrm{x}_{5} \mathrm{~N}_{2}
$$

where $\mathrm{CH}_{0.371} \mathrm{O}_{0.071}$ is the char molecule calculated from the char elemental analysis reported in Table 2.

Table 2: $\quad$ Char elemental analysis.

\begin{tabular}{cc}
\hline Elemental analysis & \% wt, dry \\
\hline $\mathrm{C}$ & 54.2 \\
$\mathrm{H}$ & 1.7 \\
$\mathrm{O}$ & 5.2 \\
Ash & 39 \\
\hline
\end{tabular}

The mass balance for the elements forming the fuel is:

$$
\begin{array}{lll}
\mathrm{C} & \rightarrow & \mathrm{x}_{1}+\mathrm{x}_{3}+\mathrm{x}_{4}=1 \\
\mathrm{H} & \rightarrow & 2 \mathrm{x}_{2}+4 \mathrm{x}_{4}=0.371+2 \mathrm{w} \\
\mathrm{O} & \rightarrow & \mathrm{x}_{2}+2 \mathrm{x}_{3}=0.071+2 \mathrm{y}+\mathrm{w} \\
\mathrm{N} & \rightarrow & \mathrm{x}_{5}=\mathrm{cost}
\end{array}
$$


where $\mathrm{y}$ is related to the equivalent ratio, and $\mathrm{w}$ is the amount of water vapor used as gasification agent. The total amount of water is conserved:

$$
\mathrm{x}_{2}=\lambda \mathrm{x}_{3}+\mathrm{w}
$$

where $\lambda=\mathrm{H}_{2} \mathrm{O} / \mathrm{CO}_{2}$ is the ratio of water and carbon dioxide production.

Four gasification reactions were considered [5]:

$$
\begin{aligned}
& \text { 1) } \mathrm{C}+\mathrm{CO}_{2} \rightarrow 2 \mathrm{CO} \\
& \text { 2) } \mathrm{C}+\mathrm{H}_{2} \mathrm{O} \rightarrow \mathrm{CO}+\mathrm{H}_{2} \\
& \text { 3) } \mathrm{C}+2 \mathrm{H}_{2} \rightarrow \mathrm{CH}_{4} \\
& \text { 4) } \mathrm{CH}_{4}+\mathrm{H}_{2} \mathrm{O} \rightarrow \mathrm{CO}+3 \mathrm{H}_{2}
\end{aligned}
$$

The reaction rates were considered to follow an Arrhenius temperature dependence and to be proportional to the difference between the actual and the equilibrium reactant partial pressure $\left(P_{i}\right)[\mathrm{Pa}]$ :

$$
\begin{gathered}
r_{1}=C_{R F} \cdot A_{1} \cdot n \cdot \exp \left(-\frac{E_{1}}{R T}\right) \cdot\left(P_{C O_{2}}-\frac{P_{C O}^{2}}{K_{1}}\right) \\
r_{2}=C_{R F} \cdot A_{2} \cdot n \cdot \exp \left(-\frac{E_{2}}{R T}\right) \cdot\left(P_{H_{2} O}-\frac{P_{C O} \cdot P_{H_{2}}}{K_{2}}\right) \\
r_{3}=C_{R F} \cdot A_{3} \cdot n \cdot \exp \left(-\frac{E_{3}}{R T}\right) \cdot\left(P_{H_{2}}^{2}-\frac{P_{C H_{4}}}{K_{3}}\right) \\
r_{4}=C_{R F} \cdot A_{4} \cdot n \cdot \exp \left(-\frac{E_{4}}{R T}\right) \cdot\left(P_{C H_{4}} \cdot P_{H_{2} O}-\frac{P_{C O} \cdot P_{H_{2}}^{3}}{K_{4}}\right)
\end{gathered}
$$

where $A$ and $E\left[\mathrm{~J} \mathrm{~mol}^{-1}\right]$ are the reaction Arrhenius parameters, $n\left[\mathrm{~mol} \mathrm{~m}{ }^{-3}\right]$ the molar concentration of gaseous species, $C_{R F}$ the char reactivity factor which was estimated from experimental data as described below and $K_{j}$ the equilibrium constants for each reaction, calculated from the Gibbs energy of reaction:

$$
\ln K_{j}=-\frac{\Delta G_{j}}{R T}
$$

The constant $C_{R F}$ is the char reactivity factor that represents the reactivity of different types of char. This parameter affects the species production rate and the temperature profile and was obtained by fitting the temperature experimental curve as explained in the next section.

The chemical species considered in this work are $\mathrm{CO}, \mathrm{CO}_{2}, \mathrm{CH}_{4}, \mathrm{H}_{2}, \mathrm{H}_{2} \mathrm{O}$ and $\mathrm{N}_{2}$. For each species $i$ the mass balance equation is:

$$
\frac{d\left(n_{i} v\right)}{d z}=R_{i}
$$

where $z$ is the bed axial coordinate, $v\left[\mathrm{~m} \mathrm{~s}^{-1}\right]$ the superficial gas velocity and $R_{i}$ $\left[\mathrm{mol} \mathrm{m}^{-3} \mathrm{~s}^{-1}\right]$ is the net rate of formation and is reported in Table 3 . 
Table 3: $\quad$ Net rate of production of the different gaseous species.

\begin{tabular}{cc}
\hline Species & $R_{i}\left[\mathrm{~mol} \mathrm{~m}^{-3} \mathrm{~s}^{-1}\right]$ \\
\hline $\mathrm{N}_{2}$ & 0 \\
$\mathrm{CO}_{2}$ & $-\mathrm{r}_{1}$ \\
$\mathrm{CO}$ & $2 \mathrm{r}_{1}+\mathrm{r}_{2}+\mathrm{r}_{4}$ \\
$\mathrm{CH}_{4}$ & $\mathrm{r}_{3}-\mathrm{r}_{4}$ \\
$\mathrm{H}_{2} \mathrm{O}$ & $-\mathrm{r}_{2}-\mathrm{r}_{4}$ \\
$\mathrm{H}_{2}$ & $\mathrm{r}_{2}-2 \mathrm{r}_{3}+3 \mathrm{r}_{4}$ \\
\hline
\end{tabular}

The variation of the temperature $(T[\mathrm{~K}])$ on the axial coordinate was calculated by an energy balance:

$$
\frac{d T}{d z}=\frac{1}{v \cdot \sum_{i} n_{i} c_{i}}\left(-\sum_{j} r_{j} \cdot \Delta H_{j}-v \frac{d P}{d z}-P \frac{d v}{d z}-\sum_{i} R_{i} c_{i} T\right)
$$

where $-\sum_{j} r_{j} \Delta H_{j}$ is the energy released by the chemical reaction $j, c_{i}$ $\left[\mathrm{J} \mathrm{mol}^{-1} \mathrm{~K}^{-1}\right]$ the molar heat capacity of the specie $i$ and $P[\mathrm{~Pa}]$ the total pressure.

To complete the modelization of the gasifier, an equation for the pressure gradient along the bed and for the variation of the superficial gas velocity are needed. The pressure gradient is a function of the superficial gas velocity and it was derived from the Ergun equation [6]:

$$
-\frac{d P}{d z}=\frac{150 \mu(1-\varepsilon)^{2}}{D_{P}^{2} \varepsilon^{3}} v+\frac{1.75 \rho(1-\varepsilon)}{D_{P} \varepsilon^{3}} v^{2}
$$

where $\varepsilon$ is the void fraction of the bed, $D_{P}[\mathrm{~m}]$ the particle diameter, $\mu$ $\left[\mathrm{kg} \mathrm{m}^{-1} \mathrm{~s}^{-1}\right]$ fluid viscosity and $\rho\left[\mathrm{kg} \mathrm{m}^{-3}\right]$ the fluid mass density.

The expression for the velocity gradient was obtained by differentiating the ideal gas law:

$$
\frac{d v}{d z}=\frac{1}{\sum_{i} n_{i} c_{i}+n R}\left(\frac{\sum_{i} n_{i} c_{i} \sum_{i} R_{i}}{n}-\frac{\sum_{j} r_{j} \Delta H_{j}}{T}-\frac{d P}{d z}\left(\frac{v}{T}+\frac{v \sum_{i} n_{i} c_{i}}{P}\right)-\sum_{i} R_{i} c_{i}\right)
$$

We obtained a system of nine coupled first order differential equations including nine variables: concentrations of the six considered species, temperature, pressure and velocity.

To make the model time dependent, the variation of the bed length as a function of time was calculated experimentally.

\subsection{Char reactivity factor and bed length consumption rate determination}

To determine the bed length consumption rate and the CRF factor, experimental tests on a smaller tubular quartz reactor heated by an electrical resistance were performed. The same operative conditions, scaled to the size of the smaller reactor, were reproduced. Four thermocouples were disposed at 0, 0.5, 1.2 and $2.6 \mathrm{~cm}$ along the reactor axial coordinate. The bed consumption rate $(\alpha)$ was calculated as:

$$
H(t)=-\alpha \times t+H_{0} \quad \alpha=0.0015 \mathrm{~cm} / \mathrm{s}
$$

where $H(t)$ and $H_{0}=5 \mathrm{~cm}$ are the bed length as a function of time and the bed length initial value, respectively. 
A curve of the gasification temperature trend is reported in Figure 2. The time needed for the complete gasification was calculated considering that the end of gasification occurs when the temperature is almost constant in the reactor. In Figure 3, three temperature profiles are reported. The curve at $250 \mathrm{~s}$ represents the beginning of the process. The combustion zone goes from 0 to $0.5 \mathrm{~cm}$ where the temperature is higher and then the endothermic gasification reactions take place and the temperature decreases. At $\mathrm{t}=3500 \mathrm{~s}$ the temperature is almost constant along the bed height and we considered the process finished.

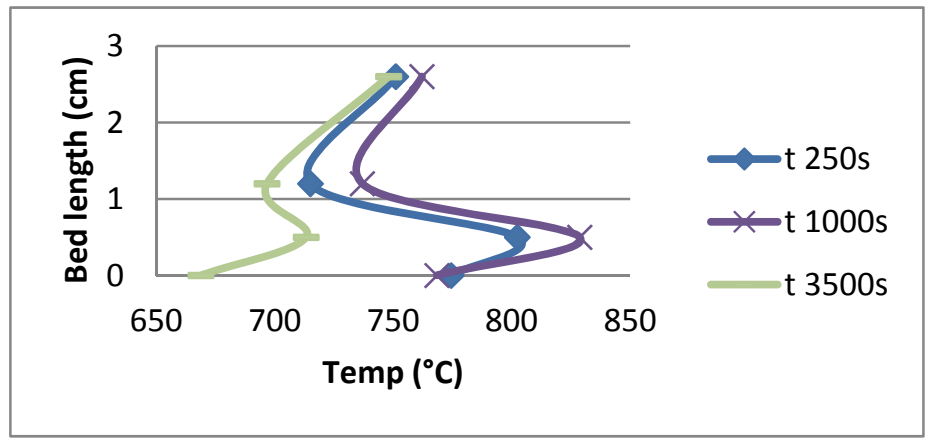

Figure 2: Temperature profile along the gasifier axis at three different residence times.

The char reactivity factor was calculated fitting the gasification temperature profile obtained in the tubular quartz reactor. In Figure 3 the experimental and fitted data are compared, showing a good agreement. The $C_{R F}$ was measured to be 2000 .

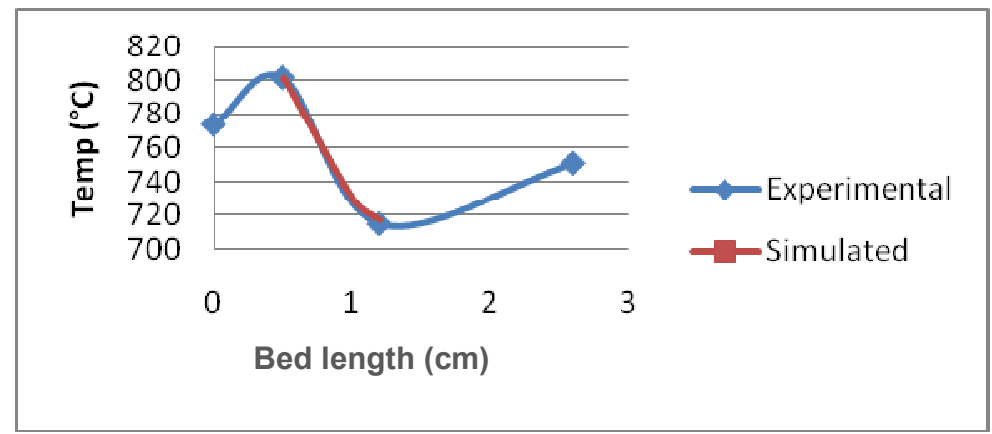

Figure 3: Comparison between experimental and simulated temperature profile as a function of bed length.

\section{Results and discussions}

In up-draft fixed-bed gasifier, the combustible and the oxidant flow countercurrently, the fuel is introduced at the top of the gasifier and the oxidant at the 


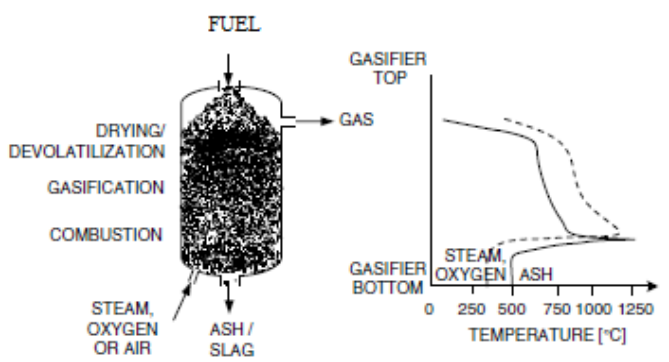

Figure 4: $\quad$ Up-draft gasifier and temperature profile [7].

bottom. In Figure 4 a generic representation an up-draft gasifier with the typical temperature profile is reported.

When the fuel is injected, it is dried and then the pyrolysis process occurs. The char forms a fixed bed in the reactor where the gasification and the combustion reactions take place. The combustion zone is the first zone from the bottom of the reactor and the exothermic reactions make the process autothermal. The raw gas exits at the top of the gasifier and is laden with pyrolysis products such as tar, oil and light hydrocarbons. Thus to complete the gasification reactions and to allow the tar cracking, a reforming unit is generally placed after the gasifier.

Two types of experimental test were performed. First a complete gasification, using the reactor as an updraft gasifier was made. In Figure 5 the concentration profiles of $\mathrm{CH}_{4}, \mathrm{CO}$ and $\mathrm{CO}_{2}$ of a complete updraft gasification process are reported. It can be noticed that the pyrolysis and the gasification processes occurs into two separated steps: the pyrolysis process takes place in the first $1000 \mathrm{~s}$, i.e. during methane production. The gasification occurs afterwards until the $\mathrm{CO}$ concentration is higher than the $\mathrm{CO}_{2}$. The $\mathrm{CO}$ concentration becomes smaller than the $\mathrm{CO}_{2}$ one as the bed height decreases and the $\mathrm{CO}_{2}$, produced by the combustion, does not have enough time to react with the residue char.

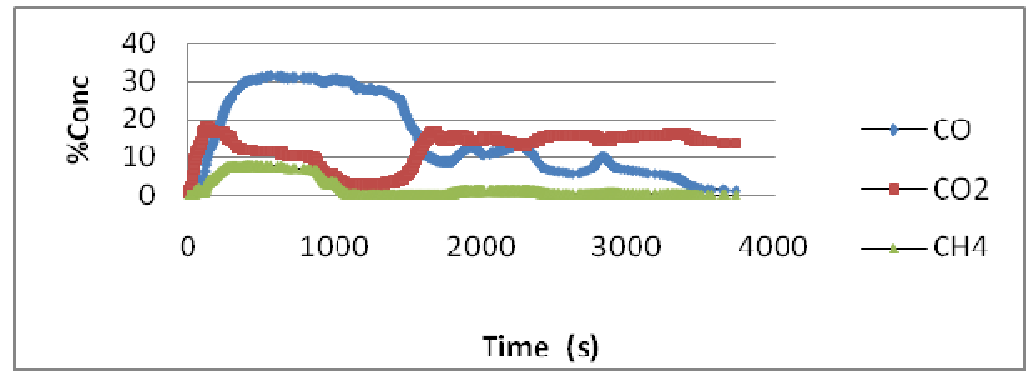

Figure 5: Concentration profile of a complete up-draft gasifier.

Since we needed experimental data on the gasification process alone, we split the process into two parts: the pyrolysis made at $850^{\circ} \mathrm{C}$ in an inert atmosphere and the gasification in a fixed bed. 
The results of the pyrolysis are reported in Table 4. The volatile concentrations were calculated before and after the reforming reactor. The amount of tar collected before the reforming reactor was calculated to be $30 \%$ of the volatile matter and the hydrogen concentration is $9 \%$. After the reforming unit, it can be noticed a great reduction of the tar amount that is converted in lighter species. The reforming unit converts most of the tar enriching the gas in hydrogen and methane. Thus the reforming reactor is fundamental to reduce the tar quantity that can create problems in the following zones of the plant.

Table 4: $\quad$ Pyrolysis gas and tar concentration.

\begin{tabular}{cccccc}
\hline & $\mathrm{CO}$ & $\mathrm{CO} 2$ & $\mathrm{CH} 4$ & $\mathrm{H} 2$ & Tar \\
\hline Before reforming & $21 \%$ & $15 \%$ & $11.4 \%$ & $9 \%$ & $30 \%$ \\
After reforming & $25 \%$ & $15 \%$ & $16 \%$ & $19 \%$ & $5 \%$ \\
\hline
\end{tabular}

The model was validated with experimental data. In Figure 6, the comparison between simulated and experimental data is reported, showing a good agreement.

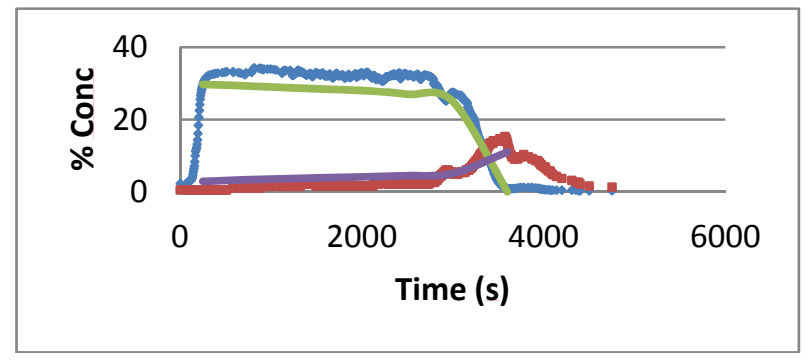

Figure 6: Experimental $\mathrm{CO}$ (blue line) and $\mathrm{CO}_{2}$ (red line) profile compared with $\mathrm{CO}$ (green line) and $\mathrm{CO}_{2}$ (violet line) simulated profile obtained for an $\mathrm{ER}=0.6, T=1100 \mathrm{~K}$ and $30 \%$ of steam.

The developed model was used to predict the gas composition in order to optimize the operative conditions that gave the best syngas composition. In Table 5 the simulated gas compositions obtained varying the ER, the steam air ratio and the temperature are reported.

Table 5: Simulated results of the syngas composition expressed in $\%$ in volume.

\begin{tabular}{cccccc}
\hline ER & $\mathrm{T}(\mathrm{K})$ & $\mathrm{O}_{2}$ steam $/ \mathrm{O}_{2}$ air & $\% \mathrm{CO}$ & $\% \mathrm{CO}_{2}$ & $\% \mathrm{H}_{2}$ \\
\hline 0.5 & 1000 & $10 \%$ & 25.73 & 4.75 & 8.00 \\
0.6 & 1000 & $10 \%$ & 23.56 & 5.49 & 6.50 \\
0.7 & 1000 & $10 \%$ & 20.19 & 6.50 & 4.30 \\
\hline 0.6 & 1100 & $10 \%$ & 30.45 & 2.30 & 8.50 \\
0.7 & 1100 & $10 \%$ & 26.54 & 4.35 & 5.70 \\
\hline 0.6 & 1100 & $20 \%$ & 33.15 & 2.60 & 9.75 \\
0.7 & 1100 & $20 \%$ & 29.30 & 4.10 & 6.80 \\
\hline 0.6 & 1100 & $30 \%$ & 35.00 & 2.25 & 11.50 \\
\hline
\end{tabular}


Increasing the amount of steam and the temperature, and decreasing the ER ratio, the quality of the obtained syngas improves. However, using a low equivalent ratio can cause a problem since the gasification process becomes too slow. As expected, increasing the steam flow, the amount of hydrogen rises. This effect could not be convenient because the gasification time increases, the reactions including the water vapour are endothermic, and the steam production is an expensive operation that can reduce consistently the plant efficiency. The estimated best gas composition is $\mathrm{CO} 35 \%, \mathrm{CO}_{2} 2.25 \%$ and $\mathrm{H}_{2} 11.5 \%$, that is a typical gas composition for air gasification.

\section{Conclusions}

The gasification represents promising technology to recover energy from waste when the calorific value is low. The performed tests confirm that the pyrolysis process of ASR produces a good quality gas that can be used as fuel, and the reforming unit reduces considerably the tar amount that can cause problem in the following section of the plant. The syngas contains a low quantity of pollutant and can be sent to a purifying unit, and then used directly as a combustible or as raw materials for other processes, like the hydrogen production or the Fischer Tropsch process. The composition of the obtained syngas is in line with typical syngas composition obtained by means of air gasification. The developed model considers explicitly the time variable and accurately fits the obtained experimental data. It can be used confidently in order to optimize the operative conditions that give the best syngas composition.

\section{References}

[1] Joung, H., Seo, Y., Kim, K., Distribution of dioxins, furans, and dioxin-like PCBs in solid products generated by pyrolysis and melting of automobile shredder residues. Chemosphere 68, pp. 1636-1641, 2007.

[2] Eurostat 2009. Available at: http://epp.eurostat.ec.europa.eu/portal/page/portal/waste/data/wastestreams/e lvs [Accessed May, 18, 2010].

[3] Ciacci, L., Moreselli, L., Passarini, F., Santini, A., Vassura, I., A comparison among different automotive shredder residue treatment processes. Int J Life Cycle Assess 15, pp. 896-906, 2010.

[4] Giltrap, D.L., McKibbin, G.R.G., Barnes, R., A steady state model of gaschar reactions in a downdraft biomass gasifier. Solar Energy 74, pp. 85-91, 2003.

[5] Wang, Y., Kinoshita, C.M., Kinetic model of biomass gasification. Solar Energy 51, pp. 19-25, 1993.

[6] Ergun, S., Fluid flow through packed columns. Chem. Eng. Prog. 48, pp. 89-94, 1952.

[7] Higman, C., van der Burgt, M., Gasification. Elsevier, 2003. 